Portland State University

PDXScholar

Environmental Science and Management

Faculty Publications and Presentations

6-1-2009

\title{
Development of an ambient pressure laser-induced fluorescence instrument for nitrogen dioxide
}

Jeremy Parra

Portland State University

Linda Acha George

Portland State University

Follow this and additional works at: https://pdxscholar.library.pdx.edu/esm_fac

Part of the Environmental Sciences Commons

Let us know how access to this document benefits you.

Citation Details

J. Parra and L. George, "Development of an ambient pressure laser-induced fluorescence instrument for nitrogen dioxide”, Applied Optics, 48(18), 3355-61, 2009.

This Article is brought to you for free and open access. It has been accepted for inclusion in Environmental Science and Management Faculty Publications and Presentations by an authorized administrator of PDXScholar. Please contact us if we can make this document more accessible: pdxscholar@pdx.edu. 


\title{
Development of an ambient pressure laser-induced fluorescence instrument for nitrogen dioxide
}

\author{
Jeremy Parra ${ }^{1, *}$ and Linda A. George ${ }^{2}$ \\ ${ }^{1}$ Department of Physics, Environmental Sciences and Resources Doctoral Program, \\ Portland State University, P.O. Box 751, Portland, Oregon 97207, USA \\ ${ }^{2}$ Environmental Science Program,Portland State University, \\ P.O. Box 751, Portland, Oregon 97207, USA \\ *Corresponding author: parra@pdx.edu
}

Received 25 February 2009; accepted 22 April 2009;

posted 26 May 2009 (Doc. ID 108005); published 10 June 2009

\begin{abstract}
Concerns about the health effects of nitrogen dioxide $\left(\mathrm{NO}_{2}\right)$ and its role in forming deleterious atmospheric species have made it desirable to have low-cost, sensitive ambient measurements of $\mathrm{NO}_{2}$. We have developed a continuous-wave laser-diode laser-induced fluorescence (LIF) system for $\mathrm{NO}_{2}$ that operates at ambient pressure, thereby eliminating the need for an expensive pumping system. The current prototype system has achieved sensitivity several orders of magnitude beyond previous efforts at ambient pressure (limit of detection of $2 \mathrm{ppb}, 60 \mathrm{~s}$ averaging time). Ambient measurements of $\mathrm{NO}_{2}$ were made in Portland, Oregon using both the standard $\mathrm{NO}_{2}$ chemiluminescence method and the LIF instrument and showed good agreement $\left(r^{2}=0.92\right)$. (C) 2009 Optical Society of America

OCIS codes: $\quad 120.2440,010.1120,140.2020,300.2530,330.6100$.
\end{abstract}

\section{Introduction}

Nitrogen dioxide $\left(\mathrm{NO}_{2}\right)$ is an important chemical species in the atmosphere and in combustion processes. Concerns about the health effects of $\mathrm{NO}_{2}$ and its role in forming deleterious atmospheric species have made it desirable to have sensitive ambient measurements of $\mathrm{NO}_{2}$. Although many direct and indirect measurement techniques exist [1-ㅡ] fluorescence (LIF) has the advantage of being both a direct and sensitive measure of $\mathrm{NO}_{2}$. Several research groups have successfully implemented LIF for in situ atmospheric measurements of $\mathrm{NO}_{2}$ using the fluorescence assay with gas-expansion (FAGE) technique and have achieved excellent sensitivity at short averaging times [5,7-11]. Although laser diodes have dramatically reduced the cost and energy requirements of $\mathrm{NO}_{2}$ LIF [10], the low-pressure regime of these systems adds significant cost, energy use, and bulk via their pumping systems. We describe

0003-6935/09/183355-07\$15.00/0

(C) 2009 Optical Society of America here a continuous-wave laser-diode LIF-based approach for $\mathrm{NO}_{2}$ that operates at ambient pressure, thereby obviating the need for a high-volume pumping system. The current system has achieved sensitivity several orders of magnitude beyond previous efforts [12,13], and with further equipment improvements it promises to be a sensitive, portable, and relatively low-cost $\mathrm{NO}_{2}$ monitoring system. As with low-pressure $\mathrm{NO}_{2} \mathrm{LIF}$, this system could also potentially serve as a "backend" to $\mathrm{NO}_{2}$ systems $[6,14,15]$.

\section{Instrument Description}

Low-pressure LIF, as implemented in the FAGE technique developed by Hard et al. [16], involves the rapid expansion of sample gas, drawn through an orifice, to subambient pressures and requires a pumping system that is able to accomplish this while maintaining a substantial flow rate [8]. Because low pressure extends the fluorescence lifetime of the excited $\mathrm{NO}_{2}$, time-gated electronics can be employed to discriminate against the scattered laser photons. Sensitivities down to $15 \mathrm{ppt}$ ( $10 \mathrm{~s}$ averaging time) have been reported using this technique [5]. Table 1 
shows a comparison of LIF instrumentation including the operating pressure and the limit of detection (LOD). These systems, except those of Barnes and Kircher [13], Mann et al. [12], and this study, all operate at pressures lower than 10 Torr.

Sub-parts-per-billion sensitivities are achieved primarily through a reduction of background "noise" arising from scattered photons resulting from the laser light interacting with air molecules. When the main source of background noise is described by a Poisson distribution, the LOD, $\left[\mathrm{NO}_{2}\right]_{\min }$, is given by the following equation:

$$
\left[\mathrm{NO}_{2}\right]_{\min }=\frac{(\mathrm{SNR})}{C} \sqrt{\frac{S_{b g}}{t}}
$$

where SNR is the signal-to-noise ratio (typically $\mathrm{SNR}=2$ ), $C$ is the sensitivity of the LIF instrument (counts $\mathrm{s}^{-1} \mathrm{ppb}^{-1}$ ), $S_{b g}$ is the background signal (counts $\mathrm{s}^{-1}$ ), and $t$ is the integration time (s). The LOD improves as the square root of the background noise, which goes down linearly with pressure. More importantly, a reduction in pressure decreases the number density of "bath" molecules, which act to quench the excited molecule, thereby increasing the fluorescence lifetime, $\tau_{\mathrm{NO}_{2}}$, which is given by

$$
\tau_{\mathrm{NO}_{2}}=\frac{1}{k_{r}+\sum_{i} k_{q i} M_{i}^{q}},
$$

where $k_{r}$ is the radiative rate constant, $k_{q i}$ are the species-dependent collisional quenching rate constants, and $M_{i}{ }^{q}$ are the number density of potential quenching molecules (e.g., $\mathrm{O}_{2}, \mathrm{~N}_{2}$ ). The FAGE technique exploits this increase in lifetime to avoid detecting scattered laser photons that arrive relatively instantaneously, by waiting some time after the laser pulse to turn on the detector. Although optical filters are still needed to reduce the influence of scattering on the optical system, in time-gated FAGE LIF the fluorescence photons are measured against a very low background (e.g., 1.5 counts $\mathrm{s}^{-1}[5]$ ).
The goal for this research was the development of a LIF instrument for operation at atmospheric pressure in order to reduce instrument complexity, cost, and energy consumption. In the current system the pressure dependence of the fluorescence signal was calculated using the governing equations for a LIF signal (system values follow parameters in parenthesis), $S_{\mathrm{NO}_{2}}$, which is equal to the product of the excitation rate $\left(E_{\mathrm{NO}_{2}}\right)$, the fluorescence efficiency $\left(\Phi_{\mathrm{NO}_{2}}\right)$, and the collection efficiency $\left(C_{\mathrm{NO}_{2}}\right)$ of the detection system:

$$
S_{\mathrm{NO}_{2}}=C_{\mathrm{NO}_{2}} \times E_{\mathrm{NO}_{2}} \times \Phi_{\mathrm{NO}_{2}} .
$$

While excited $\mathrm{NO}_{2}$ emits light over a wide spectrum $(>1000 \mathrm{~nm})$, only a fraction of that light falls within the spectral window of a typical detector $(200-900 \mathrm{~nm}) . C_{\mathrm{NO}_{2}}$ represents the efficiency involved with collecting the fluorescence signal:

$$
C_{\mathrm{NO}_{2}}=\Omega \times F \times T,
$$

where $\Omega(0.038)$ is the solid angle intercepted by the collection optics for a typical off-axis design, $F(0.7)$ is the fraction of fluorescence occurring within the spectral window of the detector, and $T(0.8)$ is the fraction of transmitted fluorescence through the optics (lens and filters).

$E_{\mathrm{NO}_{2}}$ is the rate at which $\mathrm{NO}_{2}$ is excited with units of molecules $\mathrm{s}^{-1}$, and can be expressed by

$$
E_{\mathrm{NO}_{2}}=c t \int \varphi(v) \sigma(v, \text { temp, pressure }) \mathrm{d} v,
$$

where $c$ is the number density of $\mathrm{NO}_{2}$ (molecules $\left.\mathrm{cm}^{-3}\right), l(1 \mathrm{~cm})$ is the length through which laser light interacts with the gas that is within the detector's view, $\varphi\left(3 \times 10^{15}\right.$ photons $\left.\mathrm{s}^{-1} \mathrm{~cm}^{-2}\right)$ is the laser flux, and $\sigma\left(\sim 6 \times 10^{-19} \mathrm{~cm}^{2}\right.$ molecule $\left.{ }^{-1}\right)$ is the absorption cross section of $\mathrm{NO}_{2}$ at $\lambda=406.3 \mathrm{~nm}$.

\begin{tabular}{|c|c|c|c|c|c|}
\hline LIF Instrumentation & Reference & Excitation $\lambda(\mathrm{nm})$ & Radiative Lifetime $(\mu \mathrm{s})$ & Cell Pressure (Torr) & LOD $\left(p p t \min ^{-1}\right)$ \\
\hline George and O'Brien (1991) & [11] & 532 & 140 & 0.26 & 600 \\
\hline Thornton et al.(2000) & {$[\underline{5}]$} & 585 & 100 & 0.35 & 5 \\
\hline Matsumoto et al. (2001) & [్] & 523.5 & 82 & 0.7 & 125 \\
\hline Cleary et al. (2002) & {$[\overline{7}]$} & 640.2 & 330 & 0.2 & 145 \\
\hline \multicolumn{6}{|c|}{ High Pressure } \\
\hline Barnes and Kircher (1978) & [13] & $450-470$ & $\sim 100$ & $1-760$ & $>100,000$ \\
\hline Mann et al. (1995) & {$[\overline{12}]$} & $450-480$ & $\sim 100$ & 760 & $>100,000$ \\
\hline This Work & & 406.3 & $39^{a}$ & 760 & 2000 \\
\hline
\end{tabular}

$\Phi_{\mathrm{NO}_{2}}$ is a function radiative rate constant for electronically excited $\mathrm{NO}_{2}$ and the quenching rates

Table 1. Various LIF Instrumentation for $\mathrm{NO}_{2}$, Excitation Wavelength $\lambda$, Radiative Lifetime for the Transition, Operational Cell Pressure, and Limit of Detection for a 1 min Averaging Interval

${ }^{a}$ Sivakumaran et al. [18] (2001). 
[Eq. (6)]. For high pressures $\left(\sum k_{q i} M_{i} \gg k_{r}\right)$ Eq. (6) simplifies to Eq. (7), where $K_{Q}$ is a weighted average of the quenching rates, which for dry air is $\sim 6 \times$ $10^{-11} \mathrm{~cm}^{3}$ molecule ${ }^{-1} \mathrm{~s}^{-1}$ [10] and $M$ is the total number density of air molecules (molecules $\mathrm{cm}^{-3}$ ). The radiative rate constant for the fluorescence transition at $\lambda_{\text {excitation }}=406.3$ is $k_{r}=2.6 \times 10^{4} \mathrm{~s}^{-1}$ so that approximation in Eq. (7) can be made for pressures $>10$ Torr $\left(M>3.26 \times 1 \overline{0}^{17}\right.$ molecules $\left.\mathrm{cm}^{-3}\right)$ :

$$
\begin{gathered}
\Phi_{\mathrm{NO}_{2}}=\frac{k_{r}}{k_{r}+\sum_{i} k_{q i} M_{i}^{q}}, \\
\Phi_{\mathrm{NO}_{2}}=\frac{k_{r}}{K_{Q} M}, \\
E_{\mathrm{NO}_{2}} \times \Phi_{\mathrm{NO}_{2}}=\frac{k_{r}}{K_{Q}} \\
=\bar{X} \times l \int \phi(\nu) \sigma(\nu, \text { temp, pressure }) \mathrm{d} \nu .
\end{gathered}
$$

The $\mathrm{NO}_{2}$ number density, $c$, and the total number density of air, $M$, combine to yield the result that the fluorescence is proportional to the mixing ratio of $\mathrm{NO}_{2}, \bar{X}$, and does not depend on the absolute number density of $\mathrm{NO}_{2}$ at high pressures. Figure 1 shows the calculated lifetime and modeled fluorescence signal as a function of pressure with $\lambda_{\text {excitation }}=406.3 \mathrm{~nm}$. The analysis above indicates that the fluorescence yield is higher at atmospheric pressure, is pressure independent, and the yield is even higher for transitions that have short lifetimes. Low-pressure LIF succeeds by using temporal gating to discriminate against laser photons and reduce background. In this design, discrimination is achieved through optical filters. Based on Eq. (4), the expected fluorescence signal is $\sim 40$ counts s${ }^{-1} \mathrm{ppb}^{-1}$. To achieve a LOD of $1 \mathrm{ppb}$ $\mathrm{NO}_{2}$ for a $60 \mathrm{~s}$ averaging time and a $\mathrm{SNR}=2$, the background should be less than 24,000 counts $\mathrm{s}^{-1}$ [Eq. (1)]. Background reduction $\left(S_{b g} \approx 10000\right.$ counts $\mathrm{s}^{-1}$ ) was achieved through the use of high-quality long-pass filters (optical density $>5$ for $\lambda=$ $300-431 \mathrm{~nm}$ and $\% T>90$ for $\lambda=448-900 \mathrm{~nm}$ ). The instrumental design used in the current study is typical of low-pressure LIF instrumentation, which consists of a compact excitation laser system, long-pass filters, and a photomultiplier and signal processing system but without a high-volume pumping system (Fig. 2).

\section{A. Laser Choice}

The zero-pressure fluorescence lifetime, $\tau^{0}$, and the radiative rate constant are reciprocal so that Eq. (7) may be rewritten as

$$
\Phi_{\mathrm{NO}_{2}}=\frac{1}{\tau_{\mathrm{NO}_{2}}^{0} \times K_{Q} M}
$$

Therefore a fluorescence transition with a shorter lifetime would yield a greater fluorescence signal.

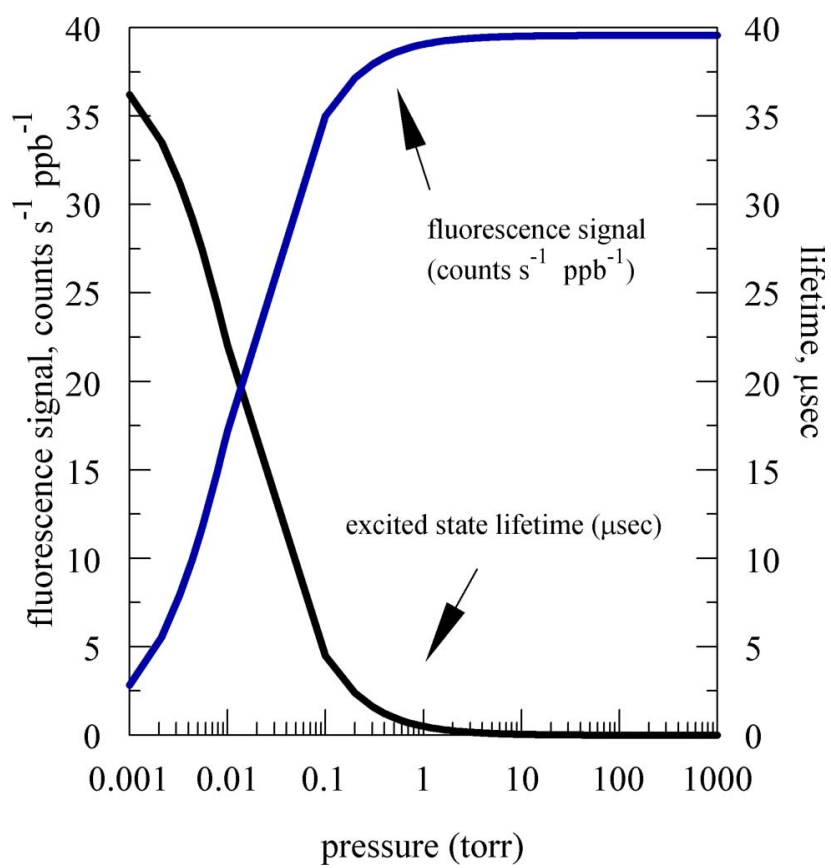

Fig. 1. (Color online) Modeled lifetime [Eq. (2)] and fluorescence signal [Eqs. (3)-(6)] dependence on cell pressure. The parameters used to model our system with $\mathrm{NO}_{2}$ excitation at $\lambda=406.3 \mathrm{~nm}$ were the detection solid angle $(\Omega=0.038)$, the fraction of fluorescence in the PMT spectral window $(F=0.7)$, the transmission of the optics $(0.8)$, the path length $(l=1 \mathrm{~cm})$, the absorption cross section $\left(\sigma=6 \times 10^{-19} \mathrm{~cm}^{2}\right.$ molecule $\left.{ }^{-1}\right)$, the radiative rate constant $\left(k_{r}=1 / \tau^{0}=2.6 \times 10^{4} \mathrm{~s}^{-1}\right)$, and the quenching constant $\left(Q=6 \times 10^{-11} \mathrm{~cm}^{3}\right.$ molecule $\left.{ }^{-1} \mathrm{~s}^{-1}\right)$.

$\mathrm{NO}_{2}$ is spectroscopically complex, leading to long lifetimes $(\sim 100 \mu \mathrm{s})$ for most fluorescence transitions [17]. The fluorescence lifetime was found to be in the range of 28 to $42 \mu \mathrm{s}$ for the $400-410 \mathrm{~nm}$ range $[\underline{18}, \underline{19}]$ as opposed to $>80 \mu \mathrm{s}$ for wavelengths used

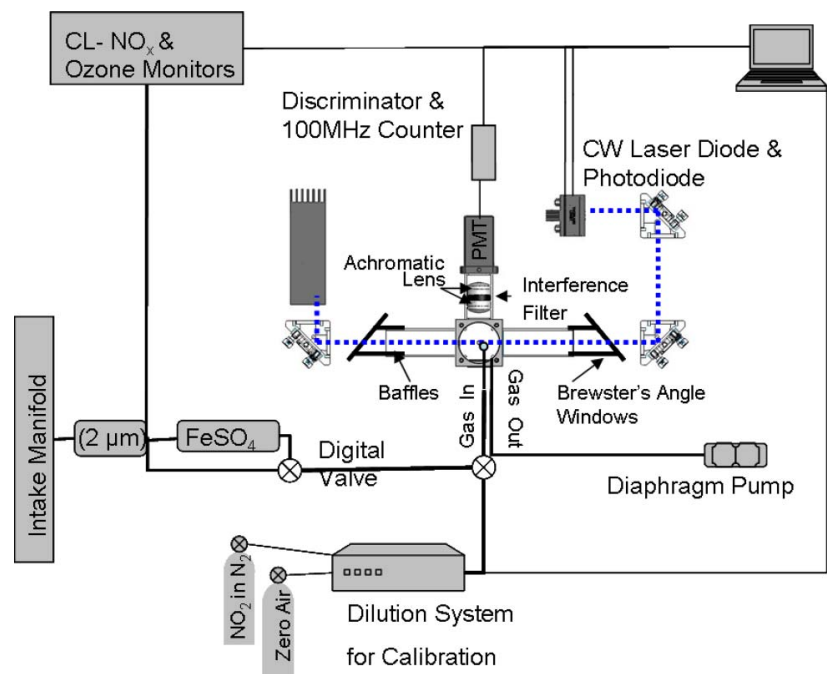

Fig. 2. (Color online) Schematic of ambient pressure LIF monitor. For calibration the dilution system with $\mathrm{NO}_{2}$ standard and zero air inputs is used to deliver various concentrations of $\mathrm{NO}_{2}$. When monitoring ambient $\mathrm{NO}_{2}$ the digital valve is switched to deliver the air sample through the $\mathrm{FeSO}_{4}$ filter for background measurements. 
in other LIF instrumentation (Table 1), thereby gaining a factor of 2 by exciting in the blue. It was advantageous to choose a wavelength further into the blue that would allow more of the red-shifted fluorescence to be within the spectral window of the detector this system used (200-900 nm). A temperature- and current-controlled $35 \mathrm{~mW}$ continuous-wave GaN semiconductor laser diode centered on $405 \mathrm{~nm}$ (Sanyo, DL 5146-152) was used for the current design. The compact and relatively inexpensive laser diode is capable of being tuned over the range of $395-415 \mathrm{~nm}$. Taketani et al. also employed a GaN laser diode tuned to $410 \mathrm{~nm}$ and, using the FAGE technique, they were able to achieve a LOD of $390 \mathrm{ppt}$ for a $60 \mathrm{~s}$ average time [10]. The typical lifetime for a laser diode operating near room temperature is $\sim 100,000 \mathrm{~h}$. In this work, a greater SNR was achieved by tuning the diode to $406.3 \mathrm{~nm}$, where the absorption cross section of $\mathrm{NO}_{2}$ is $\sim 6 \times$ $10^{-19} \mathrm{~cm}^{2}$ molecule ${ }^{-1}[20,21]$ at ambient pressure and temperature.

\section{B. Fluorescence Cell}

Although this system does not require a vacuumtight fluorescence cell to make measurements, a cell was constructed to reject ambient light and facilitate gas sampling for calibration and ambient measurements. The fluorescence chamber is an airtight cell consisting of a cubic portion $(4 \mathrm{~cm} \times 4 \mathrm{~cm} \times 4 \mathrm{~cm})$ and two side arms ending with windows held at Brewster's angle, through which the laser beam is directed. The fluorescence signal is then detected orthogonal to the laser beam. In the two faces orthogonal to the detector and laser beam there are $0.25 \mathrm{in} .(0.63 \mathrm{~cm})$ stainless steel gas ports (Swagelok) to which $0.25 \mathrm{in} .(0.63 \mathrm{~cm})$ polytetrafluoroethylene tubing is connected for gas delivery and removal.

Ambient measurements were made by connecting a diaphragm pump (Rietschel Thomas, Model 2107, capable of $46.1 \mathrm{pm}$ at 760 torr) to one of the gas ports while gas was drawn through the second gas port from an ambient roof-top intake manifold. Prior to entering the LIF chamber the sample was passed through a Teflon filter (SKC, $47 \mathrm{~mm}$ ) with a $2 \mu \mathrm{m}$ pore size to remove light-scattering particles. Background measurements (ambient air minus $\mathrm{NO}_{2}$ ) were made by passing the sample through ferrous sulfate $\left(\mathrm{FeSO}_{4}\right)$ which reduces $\mathrm{NO}_{2}$ to NO. A digitally controlled Teflon valve switched between ambient air and background.

\section{Signal Acquisition}

Two $25 \mathrm{~mm}$ achromatic lenses with antireflection coating and $30 \mathrm{~mm}$ focal length (Edmunds Optics, ACH $25 \times 30$ VIS-NIR) were used to collect and focus the fluorescence signal onto the detector. In between the two lenses, four long-pass filters with cut-on wavelengths at $440 \mathrm{~nm}$ were employed (Chroma Tech, HQ440LP) to reject scattered laser photons and transmit fluorescence photons. These filters each achieve an optical density of 5 for wavelengths shorter than $431 \mathrm{~nm}$ and a transmittance greater than $90 \%$ for wavelengths in the range of $448-900 \mathrm{~nm}$. The focal length of the first lens intersects the laser beam so that the fluorescence signal travels parallel through the long-pass filters, passes through the second lens, and is focused onto the active surface of the detector. Fluorescence photons were detected by a photomultiplier tube (PMT) with quantum efficiency above $10 \%$ to $900 \mathrm{~nm}$ (Burle electron tubes, C31034). The PMT was kept at $-25^{\circ} \mathrm{C}$ in a thermoelectric cooler (EMI Gencom, FACT 50 MKIII). The signal from the PMT was fed into a discriminator (Phillips, Model 704) with a pulse-pair resolution of $3.3 \mathrm{~ns}$. Pulses from the discriminator were counted by a $100 \mathrm{MHz}$ counter (Tennelec, TC531); the BCD output of the counter was read by a digital input/output module (Measurement Computing USB-DIO96/H) and then imported to a microcomputer via the USB bus. Data acquisition software written in-house using LabView simultaneously recorded photon (counts $\mathrm{s}^{-1}$ ) and analog signals from the laser controlling system (i.e., power, temperature). For ambient measurements a chemiluminescence NOx analyzer (Thermo Environ. Inc., Model 42c) and an ozone monitor (Daisibi Environ. Corp., Model 1003AH) sampled ambient air from the same manifold as the LIF instrument. The data was collected by an analog-to-digital converter (Measurement Computing, USB-1408FS) and imported to the data acquisition software.

\section{Possible Interferences}

A potential source of interference for LIF $\mathrm{NO}_{2}$ systems is the photolysis of ambient $\mathrm{NO}_{3}$ to $\mathrm{NO}_{2}$ during the time that it crosses the laser beam and the subsequent excitation to fluorescence of the produced $\mathrm{NO}_{2}$ [11]. For wavelengths shorter than $585 \mathrm{~nm}$ the quantum yield of $\mathrm{NO}_{2}$ from this reaction is near unity. The absorption cross section of $\mathrm{NO}_{3}$ at $406.3 \mathrm{~nm}$ is $0.2 \times 10^{-19} \mathrm{~cm} \mathrm{molecule}^{-1}$. Based on a numerical simulation of the kinetics of photodissociation, laser excitation, and fluorescence, with the flow rate and photon flux of this system, the production of $\mathrm{NO}_{2}$ from $\mathrm{NO}_{3}$ will be negligibly low even when $\left[\mathrm{NO}_{3}\right]$ is orders of magnitude greater than $\left[\mathrm{NO}_{2}\right]$. By operating in continuous-wave mode, this system has the advantage of very low photon density, thereby significantly reducing the likelihood of two photon inferences. Other species which can photodissociate to $\mathrm{NO}_{2}$ include $\mathrm{HNO}_{3}, \mathrm{~N}_{2} \mathrm{O}_{5}, \mathrm{HNO}_{4}$, peroxyacyl nitrate, and CINO $_{x}$ but, with absorption cross sections 10-100,000 times smaller than that of $\mathrm{NO}_{2}$, they will not interfere significantly at concentrations typically found in the atmosphere. The quenching rate constant for water is 6 times greater than for air [17], resulting in a LIF signal reduction of $\sim 14 \%$ for $\overline{3 \%}$ vol./vol. $\mathrm{H}_{2} \mathrm{O}$ (approximately $100 \%$ relative humidity at $298 \mathrm{~K}$ ) [10]. Simultaneous measurement of relative humidity and temperature can be used to correct for this when needed. 


\section{Results}

\section{A. Calibration}

Calibration of the LIF instrument was performed for 0-350 ppb $\mathrm{NO}_{2}$ concentrations. A standard of $46 \pm$ $5 \%$ ppm $\mathrm{NO}_{2}$ in $\mathrm{N}_{2}$ (Matheson Tri-Gas) was diluted with clean air using a multigas dilution system (Dasibi Model 5008). Clean air was produced from compressed ambient air passed through a laboratory constructed Purafil/Drierite/activated charcoal/ molecular sieve filtration pack. The resulting air is ozone free, $\mathrm{NO}_{x}<1 \mathrm{ppb}$, total volatile hydrocarbons $<1 \mathrm{ppb}$, dew point $-0.6 \mathrm{C}$. Finally, the purified air is passed through a $\mathrm{FeSO}_{4}$ cartridge in order to convert residual higher oxides of nitrogen to nitric oxide. A collocated chemiluminescence $\mathrm{NO}_{x}\left(\mathrm{CL} \quad \mathrm{NO}_{x}\right)$ (calibrated with NIST standard gases at the Oregon Department of Environmental Quality), with a stated LOD of $0.4 \mathrm{ppb}$ was used for calibrating our LIF instrument. Both instruments were allowed to stabilize at a given concentration for at least $30 \mathrm{~min}$ before using the point for calibration. The two methods are in good agreement $\left(r^{2}=0.998\right)$ as shown in Fig. 3.

The slope of this plot is $16 \pm 0.04$ counts $\mathrm{s}^{-1} \mathrm{ppb}^{-1}$, the standard error in $y$ is equivalent to $2.0 \mathrm{ppb}$ and the intercept is equivalent to $0.4 \pm 1.6 \mathrm{ppb} \mathrm{\textrm {NO } _ { 2 }}$. This sets the LOD for our instrument at $2 \mathrm{ppb}$ ( $1 \mathrm{~min}$ averaging time), and is the lowest reported concentration LIF measurement of $\mathrm{NO}_{2}$ at atmospheric pressure. Actual operating system parameters, such as actual optical collection efficiency, filter transmission, and overlap of fluorescence to PMT quantum efficiency, are likely to be the causes of the discrepancy between expected and achieved sensitivities. These also provide a good starting place for improving the sensitiv-

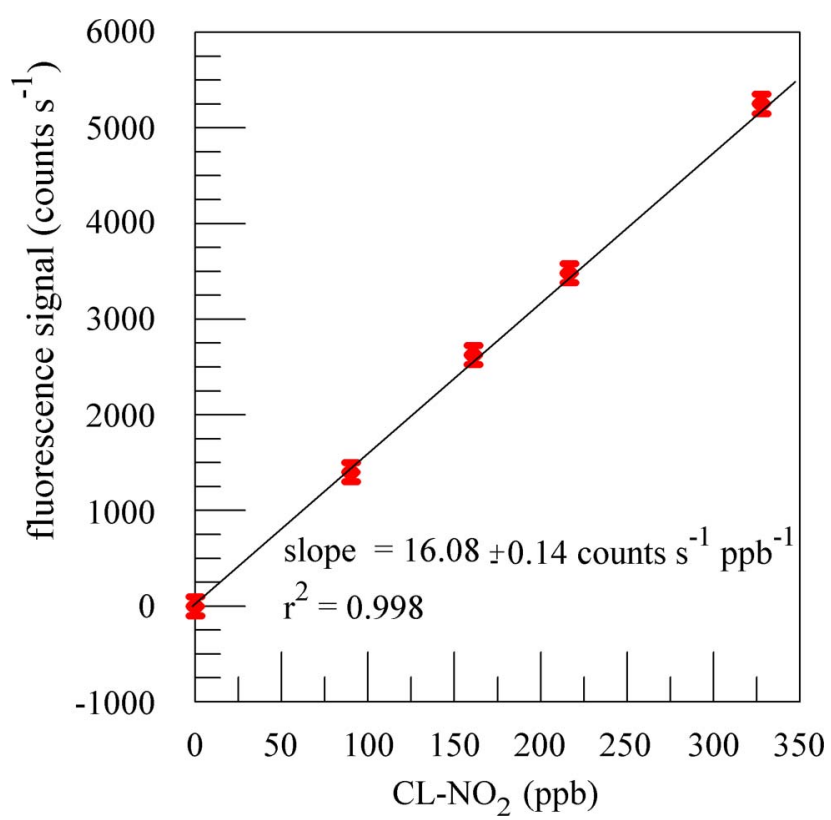

Fig. 3. (Color online) Calibration of the LIF $\mathrm{NO}_{2}$ signal (counts s$~^{-1}$ ) against a standard chemiluminescence analyzer (CL $\mathrm{NO}_{2}$ parts per billion). ity of our instrument, such as increasing the solid angle $(\Omega)$ collected by adding a curved mirror opposite of the collection lens.

\section{B. Ambient Measurements}

Ambient measurements of $\mathrm{NO}_{2}, \mathrm{NO}$, and $\mathrm{O}_{3}$ were made 10 through 14 February 2009 at Science Building 2 on Portland State University's campus (Portland, Oregon) at a $1 \mathrm{~min}$ average interval. Air was drawn through a $10 \mathrm{~m}$ long intake manifold $(15 \mathrm{~cm}$ diameter) from the rooftop, approximately $40 \mathrm{~m}$ above street level (the top of the intake is $2 \mathrm{~m}$ above the roof surface). The I-405 expressway runs $200 \mathrm{~m}$ west and south of the building. Our LIF instrument and $\mathrm{CL} \mathrm{NO}_{x}$ and ozone analyzers sampled from this manifold via $0.25 \mathrm{in} .(0.63 \mathrm{~cm}$

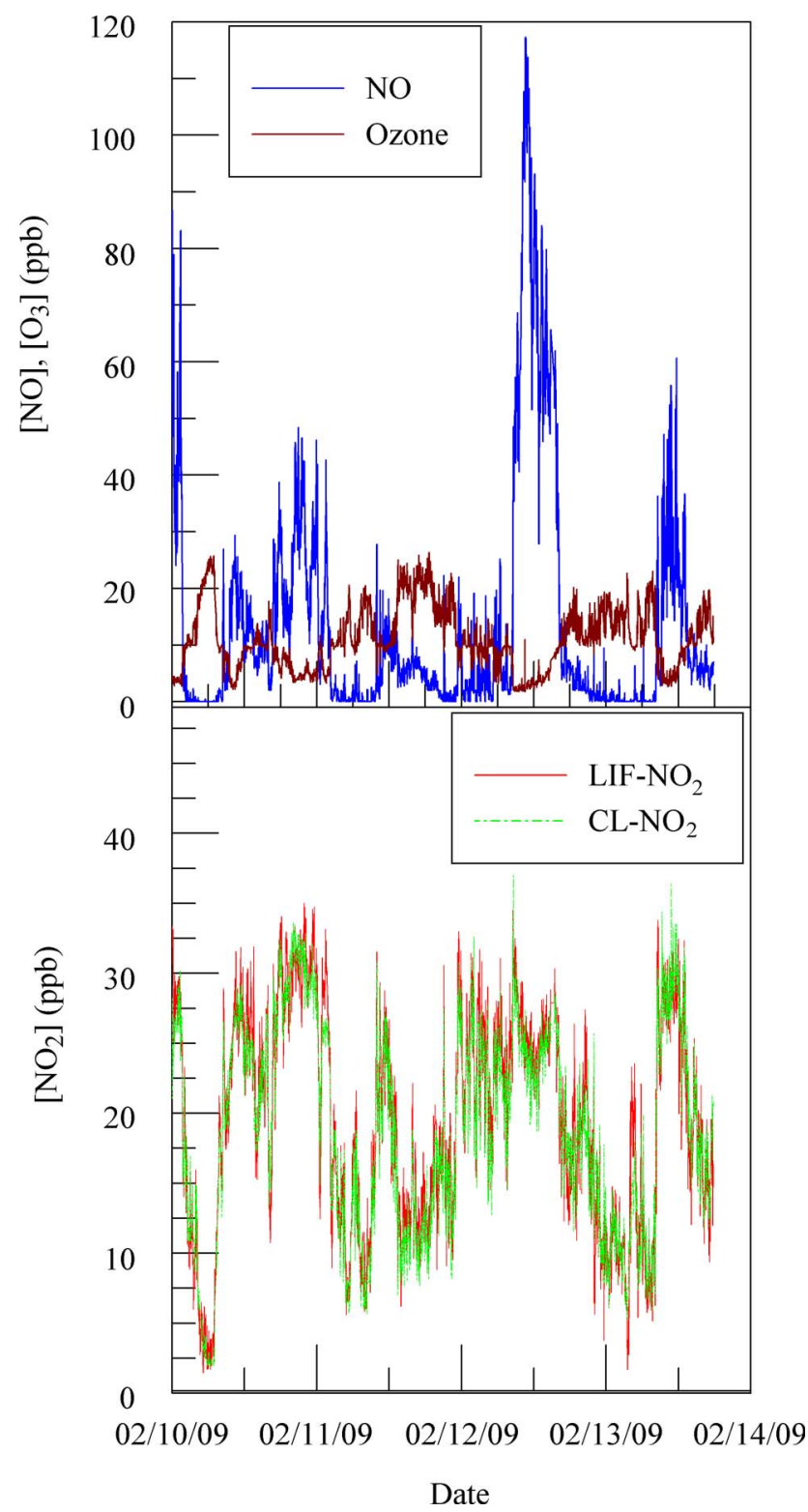

Fig. 4. (Color online) Ambient measurements of ozone, NO, CL $\mathrm{NO}_{2}$, and LIF $\mathrm{NO}_{2}$ made 10 through 14 February 2009 at the Portland State University campus Science Building 2 near the I-405 expressway. 
perfluoroalkoxy tubing. A Teflon filter with a pore size of $2 \mu \mathrm{m}$ (SKC, $47 \mathrm{~mm}$ ) was used in front of the LIF sampling tube (the same as the one integrated into the $\mathrm{CL}-\mathrm{NO}_{x}$ system). A background measurement was made once every half-hour for $5 \mathrm{~min}$ by passing the sample through a filter of $\mathrm{FeSO}_{4}$ to convert $\mathrm{NO}_{2}$ to $\mathrm{NO}$.

The ambient data is presented with a 1 min averaging time for all instruments. Figure 4 shows the good agreement between the two $\mathrm{NO}_{2}$ methods $\left(r^{2}=0.92\right.$, slope $=0.98$, intercept $\left.=0.7 \mathrm{ppb}\right)$. It is notable that the relatively high frequency changes in $\mathrm{NO}_{2}$ levels are reproduced by both instruments. The wind direction during this period is generally from the East with an average temperature of $\sim 5^{\circ} \mathrm{C}$; these winds originate from the Columbia River Gorge [22]. Nitrogen oxide and ozone anticorrelation is evident during this period. The high NO period on 12 February 2009 is attributable to the accumulation of $\mathrm{NO}$ emissions into the airshed during a low ventilation period (high-pressure system with very low wind speed). Since very little photochemistry is occurring during the overcast days of this period, oxidation of $\mathrm{NO}$ to $\mathrm{NO}_{2}$ is limited to ozone titration.

\section{Conclusion}

We have described a continuous-wave laser-diode LIF-based approach for $\mathrm{NO}_{2}$ that can be operated at atmospheric pressure. The use of high-quality optical filters has facilitated low-concentration detection of $\mathrm{NO}_{2}$ using atmospheric pressure LIF by providing substantial discrimination against scattered laser photons without the use of time-gated electronics, which add complexity and cost to the LIF instrumentation. This improvement allows operation at atmospheric pressure with a low-cost diaphragm sampling pump.

Although chemiluminescence detection of $\mathrm{NO}_{2}$ has known and potentially significant interferences, it is the most common method for in situ ambient regulatory monitoring of $\mathrm{NO}_{2}$. LIF offers a direct and sensitive method for ambient $\mathrm{NO}_{2}$, but current systems are complex and costly to operate. By operating at higher pressures this system lowers the cost and complexity of LIF for in situ ambient detection of $\mathrm{NO}_{2}$. This system can be utilized as a "backend" detector of an $\mathrm{NO}_{y}$ ambient monitor. Since this $\mathrm{NO}_{2}$ system does not require an expensive high-capacity pump, separate cells for each constituent of $\mathrm{NO}_{y}$ can be employed, thereby eliminating the complexity and potential chemical artifacts associated with switching between $\mathrm{NO}_{y}$ modes.

In summary, we have developed a LIF instrument for $\mathrm{NO}_{2}$ detection which may operate at atmospheric pressure and has a limit of detection of $2 \mathrm{ppb}$ $(\mathrm{SNR}=2)$ with an averaging interval of $60 \mathrm{~s}$. With improvements in the optical train, it is expected that this system will easily achieve sub-parts-per-billion detection limits, making it suitable for ambient measurements of $\mathrm{NO}_{2}$. Tuning of the laser on-off the $\mathrm{NO}_{2}$ absorption peak (currently not possible with our system) will eliminate the need for $\mathrm{FeSO}_{4}$ for background measurements. This system also has potential application for other fields where direct and nonintrusive measurements of $\mathrm{NO}_{2}$ are needed, such as flame, combustion, and surface chemistry.

\section{References}

1. L. N. Lamsal, R. V. Martin, A. van Donkelaar, M. Steinbacher, E. A. Celarier, E. Bucsela, E. J. Dunlea, and J. P. Pinto, "Ground-level nitrogen dioxide concentrations inferred from the satellite-borne ozone monitoring instrument," J. Geophys. Res. D 113, D16308 (2008).

2. J. S. Gaffney, R. M. Bornick, Y. H. Chen, and N. A. Marley, "Capillary gas chromatographic analysis of nitrogen dioxide and pans with luminol chemiluminescent detection," Atmos. Environ. 32, 1445-1454 (1998).

3. N. A. Marley, J. S. Gaffney, R. V. White, L. Rodriguez-Cuadra, S. E. Herndon, E. Dunlea, R. M. Volkamer, L. T. Molina, and M. J. Molina, "Fast gas chromatography with luminol chemiluminescence detection for the simultaneous determination of nitrogen dioxide and peroxyacetyl nitrate in the atmosphere," Rev. Sci. Instrum. 75, 4595-4605 (2004).

4. J. Hargrove, L. Wang, K. Muyskens, M. Muyskens, D. Medina, S. Zaide, and J. Zhang, "Cavity ring-down spectroscopy of ambient $\mathrm{NO}_{2}$ with quantification and elimination of interferences," Environ. Sci. Technol. 40, 7868-7873 (2006).

5. J. A. Thornton, P. J. Wooldridge, and R. C. Cohen, "Atmospheric $\mathrm{NO}_{2}$ : in situ laser-induced fluorescence detection at parts per trillion mixing ratios," Anal. Chem. 72, 528539 (2000).

6. K. C. Clemitshaw, "A review of instrumentation and measurement techniques for ground-based and airborne field studies of gas-phase tropospheric chemistry," Crit. Rev. Environ. Sci. Technol. 34, 1-108 (2004).

7. P. A. Cleary, P. J. Wooldridge, and R. C. Cohen, "Laser-induced fluorescence detection of atmospheric $\mathrm{NO}_{2}$ with a commercial diode laser and a supersonic expansion," Appl. Opt. 41, 69506956 (2002).

8. C. Fong and W. H. Brune, "A laser induced fluorescence instrument for measuring tropospheric $\mathrm{NO}_{2}$," Rev. Sci. Instrum. 68, 4253-4262 (1997).

9. J. Matsumoto, J. Hirokawa, H. Akimoto, and Y. Kajii, "Direct measurement of $\mathrm{NO}_{2}$ in the marine atmosphere by laserinduced fluorescence technique," Atmos. Environ. 35, 28032814 (2001).

10. F. Taketani, M. Kawai, K. Takahashi, and Y. Matsumi, "Trace detection of atmospheric $\mathrm{NO}_{2}$ by laser-induced fluorescence using a GaN diode laser and a diode-pumped YAG laser," Appl. Opt. 46, 907-915 (2007).

11. L. A. George and R. J. O. O'Brien, "Prototype FAGE determination of $\mathrm{NO}_{2}$," J. Atmos. Chem. 12, 195-209 (1991).

12. B. A. Mann, R. F. White, and R. J. S. Morrison, "Detection and imaging of nitrogen dioxide with the degenerate four-wavemixing and laser-induced-fluorescence techniques," Appl. Opt. 35 (3), p. 475-481 (1996).

13. R. H. Barnes and J. F. Kircher, "Laser $\mathrm{NO}_{2}$ fluorescence measurements in flames,” Appl. Opt. 17, 1099-1102 (1978).

14. E. J. Williams, K. Baumann, J. M. Roberts, S. B. Bertman, R. B. Norton, F. C. Fehsenfeld, S. R. Springston, L. J. Nunnermacker, L. Newman, K. Olszyna, J. Meagher, B. Hartsell, E. Edgerton, J. R. Pearson, and M. O. Rodgers, "Intercomparison of ground-based NOy measurement techniques," J. Geophys. Res. D 103, 22261-22280 (1998).

15. J. Hargrove and J. Zhang, "Measurements of $\mathrm{NO}_{x}$, acyl peroxynitrates, and $\mathrm{NO}_{y}$ with automatic interference corrections 
using a $\mathrm{NO}_{2}$ analyzer and gas phase titration," Rev. Sci. Instrum. 79 (4) (2008).

16. T. M. Hard, R. J. O'Brien, C. Y. Chan, and A. A. Mehrabzadeh, "Tropospheric free radical determination by FAGE," Environ. Sci. Technol. 18, 768-777 (1984).

17. V. M. Donnelly and F. Kaufman, "Fluorescence lifetime studies of $\mathrm{NO}_{2}$. II. Dependence of the perturbed 2B2 state lifetimes on excitation energy," J. Chem. Phys. 69, 1456-1460 (1978).

18. V. Sivakumaran, K. P. Subramanian, and V. Kumar, "Lifetime measurements of $\mathrm{NO}_{2}$ in the predissociation region 399-416 nm," J. Quant. Spectrosc. Radiat. Transfer 69, 519-524 (2001).

19. V. Sivakumaran, K. P. Subramanian, and V. Kumar, "Selfquenching and zero-pressure lifetime studies of $\mathrm{NO}_{2}$ at
465-490, 423-462 and 399-416 nm,” J. Quant. Spectrosc. Radiat. Transfer 69, 525-534 2001.

20. A. C. Vandaele, C. Hermans, S. Fally, M. Carleer, R. Colin, M. F. Mérienne, A. Jenouvrier, and B. Coquart, "High-resolution Fourier transform measurement of the $\mathrm{NO}_{2}$ visible and nearinfrared absorption cross sections: Temperature and pressure effects," J. Geophys. Res. D 107, 4348 (2002).

21. A. C.Vandaele, C. Hermans, S. Fally, M. Carleer, M. F. Mérienne, A. Jenouvrier, B. Coquart, and R. Colin, "Absorption crosssections of $\mathrm{NO}_{2}$ : simulation of temperature and pressure effects," J. Quant. Spectrosc. Radiat. Transfer 76, 373-391 (2003).

22. M. C. Green, J. Xu, and N. Adhikari, "Transport of atmospheric aerosol by gap winds in the Columbia River gorge," J. Appl. Meteor. Clim. 47, 15-26 (2008). 